\title{
Speaks's Reduction of Propositions to Properties: a Benacerraf Problem
}

\author{
T. Scott Dixon \\ Ashoka University \\ ts.dixon@ashoka.edu.in
}

\author{
Cody Gilmore \\ University of California, Davis \\ gilmore@ucdavis.edu
}

\section{Introduction}

Jeff Speaks (2014) has recently defended the view that propositions are properties: the proposition that grass is green is the property being such that grass is green, the proposition that snow is white is being such that snow is white, and so on. We argue that there is no reason to prefer Speaks's theory to analogous but competing theories that identify propositions with, say, 2 -adic or 17 -adic relations of the relevant sort, and we conclude that none of these theories is true. This style of argument derives from Benacerraf's (1965) objection to the view that numbers are sets, and it has been deployed by, e.g., Bealer (1993), Moore (1999), Moltmann (2013), and King (2007) as an objection to the view that propositions are n-tuples, sets of worlds, or functions from worlds to truth values, and by Caplan and Tillman (2013) as an objection to King's view that propositions are facts of a special sort. ${ }^{2}$ We offer our argument as an objection to any Speaks-style view according to which propositions are unsaturated (non-0-adic) relations.

\footnotetext{
1 Moore (1999) claims that arbitrariness considerations count against every reductionist theory of propositions, but he gives little support for the full generalization, which is too strong on its face. One might, e.g., have independent reason to think that obtaining and non-obtaining states of affairs are abundant, hyperintensionally individuated, sui generis abstract entities (Plantinga (1976)), and that states of affairs are the best candidates to which propositions might be reduced. If one then decided to identify propositions with states of affairs (contra Plantinga (1976: 145)), it would not be arbitrary to identify the proposition that grass is green with grass's being green, and so on (see Chisholm (1970) and Richard (2014)). So we hold that reductionist theories of propositions should typically be evaluated individually, and that it often takes detailed investigation to find out whether a given reduction suffers from a Benacerraf problem.

2 Jubien (2001) argues that arbitrariness problems apply even to theories like those of King (2007), who replies (2007: 127-163), and Speaks (2014). As it applies to a Speaks-style theory, however, Jubien's argument depends on the assumption that propositions are representational, which Speaks (2014: 220) denies. Our argument makes no such assumption.
} 


\section{Speaks's Theory}

We begin by comparing Speaks's theory to a more familiar view, which we call PPR:

(1) propositions, properties, and relations are (a) abundant and (b) hyperintensional: there are necessarily equivalent propositions, properties, and relations that are not identical;

(2) properties are 1-adic relations; and

(3) propositions are 0 -adic relations. ${ }^{3}$

It is notoriously hard to give a precise characterization of the abundance thesis, (1a), and we won't attempt it. ${ }^{4}$ For our purposes it will be enough to note that if (1a) is true, then

$\left(1 \mathrm{a}^{*}\right)$ almost $^{5}$ every open sentence expresses a relation. ${ }^{6}$

Speaks is favorably disposed towards (1) and (2), ${ }^{7}$ but he rejects (3) in favor of

(4) Propositions are properties; they are 1-adic, not 0-adic, relations.

According to Speaks, propositions are properties. More specifically: (i) not every property is a proposition. The property being an $x$ such that $x$ is red is not a proposition; nor is being an $x$ such that $x$ is identical with $x$. But (ii) every proposition is a property. The proposition

\footnotetext{
3 PPR is discussed by Quine (1960: 165) and endorsed by Bealer (1982: 1), Zalta (1983: 61), Menzel (1993), van Inwagen (2004: 131), and Gilmore (2014). See Dixon (Forthcoming: sect. 4) for a development of the analogies between properties, relations, and instantiation, on the one hand, and propositions and truth on the other.

${ }^{4}$ See Orilia and Swoyer (2016: sections 5.2 and 8).

${ }^{5}$ We say 'almost every' to avoid saddling PPRists with the claim that 'x does not instantiate itself' expresses a property.

${ }^{6}$ We assume that (i) if an open sentence contains exactly $\mathrm{n}$ free variables and expresses a relation of some fixed adicity, it expresses an $\mathrm{n}$-adic relation and that (ii) necessarily, no relation is both $\mathrm{m}$ - and $\mathrm{n}$-adic, where $\mathrm{m} \neq \mathrm{n}$ This leaves open the hypothesis that some relations have no fixed adicity. On the incompatibility of different adicities, see Gilmore (2013).

7 Speaks needs abundant, hyperintensional properties, and it would be ad hoc not to endorse a parallel account of other relations. Speaks expresses no reservations about (1) or (2) but does not explicitly endorse them. He singles out van Inwagen (2004), a proponent of PPR, as providing a background theory of properties that meets his needs - modulo van Inwagen's commitment to (3). Regarding (3), Speaks writes, 'I don't understand what a 0 -place property could be' (2014: 90, note 36$)$.
} 
that snow is white = being an $\mathrm{x}$ such that snow is white; the proposition that Obama is male = being an $x$ such that Obama is male; and so on.

Can we explicate the 'and so on'? It's not clear that we must in order to evaluate the theory. Speaks does not provide a fully general, precise formulation of the reductive theory, but he argues for it nonetheless, and we will not object to this policy. One can take a step toward increased generality by noting that if Speaks's theory, call it $T 1$, is true, then so is the following meta-linguistic thesis:

M1 Every instance of schema S1 is true.

S1 the proposition that $\phi=$ the 1 -adic relation being an $x$ such that $\phi$.

Granted, M1 does not capture the full strength of T1, since it says nothing about propositions that are not expressed by any sentence of English. But, in practice, everyone who endorses M1 will probably also endorse T1. So M1 is a useful proxy for T1.

Here is a final exegetical point. The properties to which Speaks reduces propositions are 'necessarily all-or-nothing' properties. In the idiom of possible worlds: for any possible world $w$ and any proposition p, either (i) at w, everything instantiates $p$, in which case $p$ is true at $w$ or (ii) at $w$, nothing instantiates $\mathrm{p}$, in which case $\mathrm{p}$ is false at $\mathrm{w}$. The true propositions at a world are the propositions that are instantiated by everything at that world, while the false propositions at a world are those that aren't instantiated by anything at that world. But some necessarily all-or-nothing properties - e.g., being self-identical - are not propositions (Speaks (2014: 90)).

\section{The Problem}

For each proposition $\mathrm{p}$, Speaks finds some 1-adic relation $r_{1}$ and claims that $p=r_{1}$. But why not instead find some 2 -adic relation $r_{2}$ and claim that $p=r_{2}$ ? Or some 17-adic relation $r_{17}$ and claim that $\mathrm{p}=\mathrm{r}_{17}$ ? $^{8}$

Let's look at the case of 2-adic relations. Let T2 be the theory that identifies propositions with certain 2-adic relations and is otherwise parallel to T1. According to T2,

\footnotetext{
${ }^{8}$ A different Benacerraf problem for Speaks: why not identify the proposition that grass is green with the 1adic, plural property being some xx such that grass is green? On plural properties, see Yi (1999).
} 
the proposition that grass is green $=$ the 2 -adic relation being an $\mathrm{x}$ and a $y$ such that grass is green; the proposition that Obama is male = being an $x$ and a $y$ such that Obama is male; and so on. Like T1, T2 is hard to state precisely, but we can take a step in that direction with

M2 Every instance of schema S2 is true.

S2 the proposition that $\phi=$ the 2 -adic relation being an $x$ and a $y$ such that $\phi$.

M2 fails to capture the full strength of T2 for the same reason that M1 fails to capture the full strength of T1. But both meta-linguistic theses can serve as useful proxies for their respective theories.

The relations to which $\mathrm{T} 2$ reduces propositions are necessarily all-or-nothing 2-adic relations: each such relation $r_{2}$ is such that, necessarily, either (i) for any $x$ and any $y, r_{2}$ is instantiated by $\mathrm{x}$ and $\mathrm{y}$, in that order, or (ii) for any $\mathrm{x}$ and any $\mathrm{y}, \mathrm{r}_{2}$ is not instantiated by $\mathrm{x}$ and $y$, in that order. The true propositions at a world, according to this view, are the propositions that everything bears to everything at that world, while the false propositions are those that nothing bears to anything at that world. T2 says that all propositions are 2adic, necessarily all-or-nothing relations, but it does not say that all such relations are propositions.

We believe that the case to be made for T1 can be made with equal plausibility for T2. For example, each theory identifies propositions with entities in which we allegedly have independent reason to believe. Speaks (2014: 77, note 12) assumes that we have independent reason to believe in abundant, hyperintensional properties, on the model of van Inwagen (2004). If he is right, then presumably we also have independent reason to believe in abundant, hyperintensional 2-adic relations, on the same model.

Further, if one finds it antecedently plausible that the proposition that $\phi$ is a structured complex having certain entities, $e e$, as constituents, then for any positive integer $\mathrm{n}$, one should also find it antecedently plausible that the $\mathrm{n}$-adic relation being an $x_{1} \ldots x_{n}$ such that $\phi$ is a similarly structured complex having ee as constituents. So neither T1 nor 
T2 forces us to depart much from antecedently plausible views (whatever they may be) about the constituents and internal structure of propositions. ${ }^{9}$

Finally, Speaks says that

\begin{abstract}
Propositions are properties which are true iff they are instantiated. Propositions are true with respect to a world $w$ iff, were $w$ actual, that property would be instantiated. . . Given this view of truth at a world, thinking of propositions as properties does not seem to require any serious revision in the way that we think about entailment relations between propositions, or semantics more generally. Propositions are necessary iff they are true with respect to every possible world; just so, on the present account, propositions are necessary iff the properties which they are, are instantiated in every possible world. One proposition $\mathrm{F}$ would entail another proposition $\mathrm{G}$ iff any world in which $\mathrm{F}$ is instantiated is also a world in which $\mathrm{G}$ is instantiated (2014: 76-77).
\end{abstract}

Likewise, T2 does not demand much revision in our views about entailment between propositions. It is also true according to T2 that "propositions are necessary iff they are true with respect to every possible world". According to T2, propositions are necessary iff the relations which they are, are "born by everything to everything in every possible world". T2 also guarantees that a "proposition F would entail another proposition G iff any world in which [something bears F to something] is also a world in which [something bears G to something]". It appears, then, that T2 shares these crucial virtues with T1.

In addition, it seems that for any obvious objection one might raise to $\mathrm{T} 2$, there will be an analogous and equally forceful objection to T1. Two examples should suffice to make this plausible.

First, T2 faces a demarcation problem. Not all 2-adic, necessarily all-or-nothing relations are propositions. For example, the relation being an $x$ and a $y$ such that $x=x$ and $y=y$ is not a proposition. How, then, can we fill in the blank in 'necessarily, $\mathrm{x}$ is a proposition if and only if ___ 'so as to make the resulting sentence both true and informative? Without an answer, T2 may seem incomplete. But as Speaks points out (2014: 89 - 90), T1 faces an analogous demarcation problem. Any solution that works for T1 should have an analogue that works for T2.

Second, given that the proposition that $2>3$ and the proposition that $1+1=5$ both exist and are not identical, $\mathrm{T} 2$ is committed to the existence of the relations, being an $\mathrm{x}$ and a $y$ such that $2>3$ and being an $x$ and a y such that $1+1=5$, that are necessarily uninstantiated

\footnotetext{
${ }_{9}^{9}$ Speaks does not make this point, but we assume that he would not object.
} 
and hyperintensionally individuated. But analogous points apply to T1.10 Simply delete each occurrence of 'and a $y$ ' in the italicized expressions, and one will have names of 1-adic relations to which $\mathrm{T} 1$ is committed and which share the potentially problematic features. So $\mathrm{T} 2$ is no worse off than $\mathrm{T} 1$ in these respects.

\section{Objections and Replies}

Objection 1. What makes $\mathrm{T} 1$ preferable to $\mathrm{T} 2$ is that $\mathrm{T} 1$ attributes a lesser adicity to propositions than T2 does. One 'adicity minimization' principle that supports this claim is:

$\mathrm{AM}_{\mathrm{p}}$ Theories according to which propositions are m-adic should, pro tanto, be preferred to theories according to which propositions are n-adic, provided that $\mathrm{m}$ is a positive natural number less than $\mathrm{n}$.

$\mathrm{AM}_{\mathrm{p}}$ puts T1 at an advantage to T2. Adicity aside, T1 is at least as good as T2. So, given $\mathrm{AM}_{\mathrm{p}}$, it follows that $\mathrm{T} 1$ is preferable overall to $\mathrm{T} 2$. In support of $\mathrm{AM}_{\mathrm{p}}$, (i) it is intuitive, and (ii) considerations of simplicity favor it: theories according to which propositions are m-adic are pro tanto simpler than, hence pro tanto preferable to, theories according to which propositions are $n$-adic, where $m$ is a positive natural number less than $n$.

We address (i) and (ii) separately.

Reply to (i). The objector takes $\mathrm{AM}_{\mathrm{p}}$ to be intuitive. Perhaps an appeal to intuition is out of place in a case like this, in which the subject matter (the adicity of propositions) is esoteric and theoretical. But suppose, with Speaks (2014: 72), that intuition does carry weight even on such topics. Then we grant that some principle in the neighborhood of $\mathrm{AM}_{\mathrm{p}}$ is intuitive. But we deny that $\mathrm{AM}_{\mathrm{p}}$ itself is intuitive.

Consider three theories. The first, $\mathrm{T} 0$, says that propositions are 0 -adic relations, in accordance with component (3) of PPR. The second, T17, says that propositions are 17-adic relations of the appropriate sort. The third, T19, says that propositions are 19-adic relations of that sort. How should we rank these theories? $\mathrm{AM}_{\mathrm{p}}$ is silent as to how $\mathrm{T} 0$

10 On necessarily uninstantiated properties, see (Speaks 2014: 77). On hyperintensional properties, see (2014: 89). 
compares to $\mathrm{T} 17$ or $\mathrm{T} 19$, but it says that T17 is preferable to T19. Both facts deserve comment.

First, it is plausible that, so far as considerations of adicity are concerned, T0 is preferable to T17 or T19. (More on this below.) So if $\mathrm{AM}_{\mathrm{p}}$ is intuitive, then so is a more general principle, call it $A M$, which results from deleting the word 'positive' in $\mathrm{AM}_{\mathrm{p}}$. Second, it is not intuitive that T17 is preferable to T19. As we see it, intuition is either agnostic on how to rank T17 and T19, or else it ranks them as equal, and equally bad. This weighs against the intuitiveness of $\mathrm{AM}_{\mathrm{p}}$ or $\mathrm{AM}$.

If any principle like $\mathrm{AM}_{\mathrm{p}}$ is intuitive, it is 0 -adicity or Bust:

0B Theories according to which propositions are 0-adic, fully saturated entities should, pro tanto, be preferred to theories according to which propositions are not fully saturated entities, i.e., are n-adic, for some $n>0$.

0B harmonizes with the view that T0 is preferable to T17 and T19, and that T17 and T19 are, if anything, equally implausible. Further, lest $0 \mathrm{~B}$ be thought to beg the question against Speaks, we can argue for it using premises acceptable to all parties. ${ }^{11}$ Consider these four expressions:

(a) __ is farther from ---- than ... is from ***

(b) __ is farther from ---- than ... is from South Bend

(c) _ _ is farther from ---- than Princeton is from South Bend

(d) _ _ is farther from Delhi than Princeton is from South Bend

They express 4-adic, 3-adic, 2-adic, and 1-adic relations, respectively. We assume that this is granted by all parties. But it provides inductive evidence that

(e) Sacramento is farther from Delhi than Princeton is from South Bend

11 Moreover, 0B does not entail that $\mathrm{T} 1$ is false, only that it has a vice. Speaks concedes that T1 has vices (2014: 78; 83 , note $24 ; 90$, note 36$)$. So he seems amenable in principle to 0B. 
expresses a 0 -adic relation. All parties also grant that (e) expresses a proposition. So, unless (e) expresses two different entities, ${ }^{12}$ it follows that at least some propositions are 0 -adic relations. Considerations of uniformity then favor the idea that all propositions are 0 -adic relations. Call this the plugging argument. Speaks may find some step in the argument to resist, but only, we think, at some cost. What the argument shows, then, is that there is theoretical pressure toward $0 \mathrm{~B}$.

Might one hold, with AM, that while it would be ideal to treat propositions as 0 -adic, it would still be better to treat them as 1 -adic than as 2-adic or 17-adic? This position is just as unintuitive as the analogous view that theories according to which horses have $\mathrm{n}$ legs are pro tanto preferable to theories according to which horses have m legs, provided that 14 $-\mathrm{n} \mid$ is less than $|4-\mathrm{m}|$. The fact that 17 is closer to 4 than 19 is doesn't make the view that horses have 17 legs pro tanto preferable to the view that horses have 19 legs. We conclude that it is $0 \mathrm{~B}$, not $\mathrm{AM}$ or $\mathrm{AM}_{\mathrm{p}}$, that is intuitive in its own right and supported by nearby data (via the plugging argument). And rather than breaking the tie between $\mathrm{T} 2$ and $\mathrm{T} 1,0 \mathrm{~B}$ merely puts both at a disadvantage to $\mathrm{T} 0$.

Reply to (ii). The objector claims that $\mathrm{T} 1$ is simpler than $\mathrm{T} 2$. There are several things one might mean by this.

(a) One might mean that $\mathrm{T} 1$ is more ontologically parsimonious than $\mathrm{T} 2$, i.e., that $\mathrm{T} 1$ posits fewer entities (or types of entity) than T2. But that is false. Strictly speaking, T2 posits the 2-adic relations that it identifies with propositions, and nothing else, just as T1 posits the 1-adic relations that it identifies with propositions, and nothing else..$^{13}$ So both are committed to an abundance of entities of a single type. Granted, T2 is plausible only to the extent that there is independent reason to believe in the 2-adic relations it posits; and any such reason will also support the 1-adic relations posited by T1. But the converse is equally true. T1 is plausible only to those who would have embraced an extreme abundance of hyperintensional 1-adic relations anyway, even if these relations hadn't been

\footnotetext{
12 If a 0 -adic relation is expressed by (e), then, just as the 1-adic relation expressed by (d) is true of Sacramento, the 0 -adic relation expressed by (e) is true simpliciter, which suggests that it is a proposition.

${ }_{13}$ Given that T2 entails that the 2-adic relation being an $x$ and a $y$ such that grass is green exists, doesn't it follow that $\mathrm{T} 2$ also entails that the property being an $x$ such that grass is green exists and is 1 -adic? We doubt it. One might reduce propositions to 2 -adic relations via $\mathrm{T} 2$ and reduce properties to 2-adic relations, by saying that the property being an $x$ such that $x$ is red = being a $y$ and an $x$ such that $x$ is red, and so on. On this (odd) view, propositions and properties are 2-adic relations of different sorts.
} 
used in a reductive theory of propositions. But, to our knowledge, no one has ever held that there are 1-adic relations such as being an $x$ such that Obama is male but no 2-adic relations such as being an $x$ and $a y$ such that Obama is male. Such a view would be highly ad hoc.

So T1 and T2 are committed to the same number of entities and to the same number of types of entities. And for either theory to be remotely plausible, the same background ontology of properties and relations is required.

(b) One might instead mean that T1 is more ideologically parsimonious than T2, i.e., that T2 invokes more bits of primitive ideology than T1. This is also doubtful. What new primitive ideology must T2 use over and above that used by T1? Both employ the same term-forming operator 'being an $x_{1} \ldots x_{n}$ such that $\phi$ '. The mere fact that T2 uses two variables where $\mathrm{T} 1$ uses only one makes no difference with respect to the primitive ideological machinery of the two theories. And even if it did, the T1-ist will have to employ two variables when forming terms that refer to 2-adic relations. It's just that, on T1, none of these relations will be propositions.

(c) Finally, one might mean that T1 is shorter than T2. Consider some instance of schema S1 (e.g., 'the proposition that grass is green = being an $\mathrm{x}$ such that grass is green') and the corresponding instance of schema S2 ('the proposition that grass is green = being an $x$ and a $y$ such that grass is green'). The former sentence is shorter than the latter. Further, consider the definitions of truth at a world, and of entailment, associated with T1. These are shorter than the corresponding definitions associated with T2.

We grant all this. But this sort of brevity is not often cited as a theoretical virtue. Moreover, if it were such a virtue, Benacerraf's original problem would not have had the impact it did. Benacerraf argued that there is no reason to identify the ordinals with the von Neumann ordinals rather than the Zermelo ordinals. Yet, the Zermelo definitions of the numbers (and any definitions given in terms of them) are shorter than the corresponding von Neumann definitions. To look at a representative example, the competing definitions of the number two are:
Zermelo:
$2=\{\{\varnothing\}\}$
von Neumann:
$2=\{\varnothing,\{\varnothing\}\}$ 
According to the Zermelo definition, 2 has only one member, which is $\{\varnothing\}$; whereas, according the von Neumann definition, 2 has two members, $\{\varnothing\}$ and $\varnothing$. This makes it plausible that the Zermelo theory is shorter than the von Neumann theory, in whatever sense $\mathrm{T} 1$ is shorter than T2. But, to our knowledge, this has never been seriously considered as a way to solve the Benacerraf problem. This, we think, is because brevity of this sort should not play a significant role in theory choice. Accordingly, it cannot solve our problem for Speaks's theory. ${ }^{14}$

Objection 2. According to T1, the proposition that grass is green = being an $\mathrm{x}$ such that grass is green. According to $\mathrm{T} 2$, that proposition = being an $\mathrm{x}$ and a $\mathrm{y}$ such that grass is green. Thus, T2 posits an additional argument place in the given proposition. Moreover, that additional argument place does no work: it brings no advantages beyond those associated with the single argument place posited by T1. Since every such argument place is a cost, T2 is costlier all things considered than T1.

Reply. We want to make two points. (i) Neither T1 nor T2 is stated in terms of argument places. As far as T1 or T2 go, one is free to deny that there are argument places. One is free, e.g., to say that loving is 2-adic but has no argument places. (Though see Gilmore: 2013 for critical discussion of various 'slot-free' treatments of adicity.)

In response, the objector might restate Objection 2 as follows: 'T2 increases the adicity of propositions, in comparison to T1, without yielding any corresponding benefit. Since theories according to which propositions are m-adic should, pro tanto, be preferred to theories according to which propositions are $n$-adic, provided that $m$ is a positive natural number less than $\mathrm{n}, \mathrm{T} 1$ is preferable overall to T2.' But this is just Objection 1, which we have already addressed.

(ii) Even if T1 and T2 were both committed to argument places, Objection 2 would still fail, for familiar reasons. Each theory is plausible only against the backdrop of

\footnotetext{
${ }^{14} \mathrm{~A}$ fourth version of the simplicity objection is that $\mathrm{T} 1$ is preferable to $\mathrm{T} 2$ because $\mathrm{T} 1$ identifies propositions with entities that have a lower adicity, and hence are simpler, than those associated with T2. We reply, first, that argument is needed for the claim that lower adicity entities are, ceteris paribus, simpler entities in some sense relevant to theory choice. (If $\mathrm{n}$ has fewer prime factors than $\mathrm{m}$, does that contribute to $\mathrm{n}$ 's being simpler than $\mathrm{m}$ ?) Second, an analogous simplicity objection applies just as forcefully to Benacerraf's original problem about numbers and sets, so our new problem for Speaks is, at worst, on par with the original.
} 
abundant realism about $n$-adic relations, for each positive natural number $n$. Together with this backdrop, T1 is committed to the same number of argument places as is T2. True, the relations that $\mathrm{T} 1$ calls propositions have fewer argument places in them than do the relations that T2 calls propositions, but both overall packages have the same ontology. So the 'additional' argument places posited by T2 are not 'additional' in any sense that harms T2 vis-à-vis T1. (Moreover, the finite Zermelo ordinals have fewer members than the corresponding finite von Neumann ordinals, but this doesn't solve Benacerraf's original problem.)

\section{Conclusion}

We have argued that there is no reason to prefer Speaks's reductionist theory of propositions, according to which propositions are properties, to certain other reductionist theories, according to which propositions are $n$-adic relations, for $n>1$. We have shown that the virtues that Speaks attributes to his own theory are shared by the alternative theories, and that the potential vices of the alternative theories have analogues that afflict that Speaks's theory. We conclude, in the manner of Benacerraf (1965), that none of these reductionist theories is true. ${ }^{15}$

\section{References}

Bealer, G. 1982. Quality and Concept. Oxford: Clarendon Press.

Bealer, G. 1993. A solution to Frege's puzzle. Philosophical Perspectives 7: 17-60.

Benacerraf, P. 1965. What numbers could not be. The Philosophical Review 74, 47-73.

Caplan, B. and C. Tillman 2013. Benacerraf's revenge. Philosophical Studies 166, 111-129.

Chisholm, R. 1970. Events and propositions. Noûs 4: 15-24.

Dixon, T. S. forthcoming. Upward grounding. Philosophy and Phenomenological Research.

Gilmore, C. 2013. Slots in universals. In. K. Bennett and D. Zimmerman, eds., Oxford Studies in Metaphysics, Vol. 8 (Oxford: Oxford University Press), pp. 187-233.

Gilmore, C. 2014. Parts of propositions. In S. Kleinschmidt, ed., Mereology and Location (Oxford: Oxford University Press), pp. 156-208.

\footnotetext{
${ }^{15}$ We would like to thank the editor and a referee for helpful comments.
} 
Jubien, M. 2001. Propositions and the objects of thought. Philosophical Studies 104: 47-62.

King, J. 2007. The Nature and Structure of Content. Oxford: Oxford University Press.

King, J., S. Soames, and J. Speaks 2014. New Thinking about Propositions. Oxford: Oxford University Press.

Menzel, C. 1993. The proper treatment of predication in fine-grained intensional logic. Philosophical Perspectives 7, 61-87.

Moltmann, F. 2013. Propositions, attitudinal objects, and the distinction between actions and products. Canadian Journal of Philosophy 43:679-701.

Moore, J. G. 1999. Propositions, numbers, and the problem of arbitrary identification. Synthese 120: 229-263.

Orilia, F. and C. Swoyer. 2016. Properties. The Stanford Encyclopedia of Philosophy (Spring 2016 Edition), Edward N. Zalta (ed.), URL = <http://plato.stanford.edu/archives/spr2016/entries/properties/>.

Plantinga, A. 1976. Actualism and possible worlds. Theoria 42: 139-160.

Quine, W. V. 1960. Word and Object. Cambridge, MA: MIT Press.

Richard, M. 2014. What are propositions? Canadian Journal of Philosophy 43: 702-719.

van Inwagen, P. 2004. A theory of properties. In D. Zimmerman, ed., Oxford Studies in Metaphysics, Vol. 1 (Oxford: Oxford University Press), pp. 107-138.

Yi, B. 1999. Is two a property? Journal of Philosophy 96: 163-190.

Zalta, E. N. 1983. Abstract Objects. Dordrecht: Reidel. 